\title{
Análisis de consistencia de caminos bidireccionales usando mediciones continuas de velocidad de operación obtenidas con GPS
}

\section{Two-lane rural highways consistency analysis using continuous operating speed measurements obtained with GPS}

\author{
Tomás Echaveguren*
}

\author{
* Universidad de Concepción, Concepción. CHILE
}

Fecha de Recepción:03/02/2012

Fecha de Aceptación:04/07/2012

PAG 55 - 70

\section{Resumen}

El análisis de consistencia permite evaluar la seguridad en caminos en base a la velocidad. Existen diversos modelos velocidad - geometría para elementos aislados de una carretera, que se utilizan para evaluar la consistencia de elementos aislados del trazado de una carretera. Por ejemplo curvas horizontales simples o en curvas de inflexión en "S".Los modelos de análisis de consistencia agregados, permiten evaluar segmentos largos de trazado, por lo que necesitan perfiles de velocidad continuos. En este caso, los modelos y mediciones puntuales de velocidad no son adecuados. Actualmente, la tecnología de posicionamiento satelital es una manera eficiente de construir perfiles de velocidad en largas distancias del trazado, siendo particularment útil para aplicar el método de Polus. Este trabajo estudia el modelo de análisis de consistencia de Polus usando perfiles continuos de velocidad. Primero se discute dicho modelo, para luego presentar la obtención y tratamiento de datos de velocidad usando modelos y mediciones directas. El método se aplicó a 5 casos de estudio en los cual se midió en terreno la velocidad y geometría con un GPS partir del cual se obtuvieron perfiles directos y teóricos de velocidad .Los datos fueron procesados con el filtro de Kalman y suavizados con el método LOESS, para luego evaluar la consistencia de cada ruta. Se concluyó que el método de Polus y los perfiles contínuos de velocidad medidos permiten obtener una calificación de segmentos largos del trazado, pero se debe segmentar adecuadamente cada trazado para evitar sub/sobre estimaciones de consistencia.

Palabras Clave: Consistencia, velocidad, GPS, caminos rurales bidireccionales

\begin{abstract}
Consistency assessment permits to study road safety regarded to speed. There exist several speed-geometry models that assessed isolated components of roads, which are used for consistency assessment of single elements of roads. For instance, single horizontal curves or reverse curves. Aggregated consistency assessment models, permit to assess long segments of roads.Therefore, continuous speed profiles are needed. In that case, speed-geometry models for single elements are not suitable. Today satellite positioning technology is an efficient way to develop continuous speed profile for long sectors of roads, particularly useful for aggregated consistency assessement. This paper study the Polus' consistency assesment model, which need as input continuous speed profiles. First, Polus' model is discussed. After a method for speed data collection and processing using in-field measurements and models is discussed. Method was applied to 5 roads using a GPS device. Data were processed with Kalman filter and smoothed with loess smoother. With the speed profile processed, filtered and smoothed, Polus' consistency method was used to estimate consistency index in each road. It was concluded that Polus' method and continuous speed profiles are suitables to rate consistency of long road segments. However, special attention should be given to road segmentation to avoid under or over-estimation of the road consistency, particularly in straight and steeped segments.
\end{abstract}

Keywords: Consistency, speed, GPS, two-lane rural roads

\section{Introduction}

Geometrical design consistency is defined as the condition that allows driver expectations to be concordant with a road geometrical design. As long as there are more consistent roads, the accident risk rate will decrease, which theoretically increases safety road rates. Assessment consistency methods for a given design include indicators, acceptance thresholds and improvement recommendations for existing roads or design alternatives (Echaveguren et al., 2009). Lamm et al. (1988) is the most popular method that proposes a consistency index based on the difference between design speeds and operation on isolated horizontal curves and reverse curves. Acceptance thresholds are also proposed to differentiate consistency rate on such roads. This method assumes that consistency of a road is essentially determined by a driver's behavior on horizontal curves, therefore it is applied to isolated components of the road.

${ }^{1}$ Autor de correspondencia / Corresponding author: 
Consequently, the combined effect of vertical and horizontal roads is unknown, as well as the effect on long tangents between curves.

\section{Operation speed profiles}

A relevant aspect for the consistency assessment is the operation speed profile. Operation speed is a direct measurement of driver's response to environmental driving behavior and especially to road geometry. For this reason, most consistency assessments intend to elaborate speed-geometry relationships. Reference is made to Echaveguren (2010) who identified at least 130 calibrated models between years 1968 and 2012. Such relationships usually describe specific behaviors. For example the relationship between speed and curvature radius regarded to half development of a horizontal curve. Above because measurement techniques usually applied for operation speeds are also specific measurements, which due to high assessment cost and technical limitations can not be broadly spread to provide a continuous data profile (at least containing a high data density). Consequently, speed profiles usually described on literature are limited to representative values from few measurement points. For instance, by using a ray-gun it is possible to obtain a semi random sample of operation speed on single isolated curves, at five different points: 2 on entrance and exit tangents and 3 on the inside of the curve. In order to cope with this limitation, some researchers have estimated longitudinal acceleration/deceleration values which allow relating speed specific data by means of kinematic equations (See Fitzpatrick and Collins (2000) or Cox and Arndt (2010). Other models such as IHSDM (Interactive Highway Safety Design Model) have established theoretical speed profiles by using fixed acceleration/ deceleration values, which together with speed-geometry equations are able to determine the decrease of operation speed compared to a previously defined projected speed. In this way IHSDM artificially builds up continuous speed profiles from models describing specific variations, thus connecting each model by means of abovementioned acceleration/deceleration values.

Such limitation on speed-geometry models as well as on consistency assessment can be avoided by using global positioning technology (GPS, GALILEO or GLONASS). Such technology enables us to build operation speed profiles by using a higher amount of speed and/or positioning data.

\section{GPS Technology and Consistency Assessment Method}

Experiences from the use of such technology are quite recent. Cafiso et al. (2005); Memon et al. (2008); Pérez et al. (2010); Zhao et al. (2011) and Rim et al. (2011) have explored such technology by using global positioning system (GPS) to develop speed - geometry models from data obtained by GPS. 
Cafiso et al. (2005) equipped a vehicle with a GPS logger in order to measure continuous speed on long road segments. Memon et al. (2008) employed a VBOX $3 i$ equipment (sub metric GPS) to measure speed on a drivers group by applying car-following technique and developed speed-geometry models for reverse curves. Pérez et al. (2010) employed a navigation GPS to register vehicles timing and positioning thus obtaining data to calculate operation speed indirectly. Afterwards, operation speed models were calibrated by considering the entrance curve tangent and the curve itself.

Zhao et al. (2011) evaluated the accuracy of GPS devices used to measure the speed of load vehicles and compared the results to ground fixed-sensors. Significant differences were not detected between both measurement methods. Rim et al. (2011) proposed a method intended to correct errors on speed readings provided by GPS. In order to do so, they used a weighed regression algorithm which later compared to exponential smoothed algorithms. From such experience they detected outliers and missing data, thus being able to correct those irregularities from GPS measurements.

Consequently, it is possible to state that GPS technology allows us to achieve speed profiles with reasonable accuracy. Those profiles enable the development of speed-geometry models used to obtain speed profiles on long road segments, thus providing comparative advantages regarding current techniques of speed profile development.

\section{Objective and scope}

The main objective of this study is to discuss Polus' consistency assessment model and its application on long road segments, based on continuous operation speed profiles obtained by means of a sub metric GPS of RTK technology (Real Time Kinematic). In the first place, the Polus' consistency assessment model is described. Afterwards the methods used to obtain speed profiles by means of predictive models and using GPS are described in detail emphasizing on methodological and operative aspects of in-field data collection, on data filtering by means of Kalman Filter method and data smoothening by means of Loess smoother. Then an application is developed for the Polus' consistency assessment model in the 5th Highway, center-south area of Chile, where operation speeds were registered by means of a GPS. A speed profile was calculated based on predictive models to later discuss obtained results.

\section{Polus'Consistency assessment model}

Consistency assessment model is an aggregated model. Contrarily to Lamm et al (1988) model, which is mainly focused on horizontal curves, Polus et al (2004) method considers a complete speed profile to evaluate longer road segments than curves and counter curves. 
Polus et al. (2004) method is based on two concepts: a) the difference between operation speed and the average operation speed of segment under study; b) standard deviation of speed alongside the segment under study.

Operation speed is estimated by a conventional method by using the 85 percentile of a speed frequency distribution. This aspect imposes higher difficulties for the method application, provided that it requires a great amount of operation speed records in order to build a speed profile. So the use of GPS technology is ahead regarding other measurement methods for operation speed.

So as to evaluate segment by segment consistency, Polus et al., elaborated the C consistency index (in $\mathrm{m} / \mathrm{s}$ ) for Equation.1. It is a dimensionless Index that depends on standard deviation of operation speed $(\sigma$, in $\mathrm{m} / \mathrm{s})$ and on the regularized area existing between the average operation speed and the operation speed profile $\left(R_{a^{\prime}}\right.$ in $\left.\mathrm{m} / \mathrm{s}\right)$.

$C=2,808 e^{-0,278 \sigma R_{a}}$

Similarly, Polus et al. (2004) suggested a consistency threshold for Equation 1 index, based on expert's judgement and applying a ranking method. Table 1 shows three thresholds.

Tabla 1. Umbrales de consistencia del modelo de Polus (Polus et al., 2004)

Table 1. Consistency thresholds for Polus' Method (Polus et al., 2004)

\begin{tabular}{||c|c|c|c||}
\hline \multirow{2}{*}{} & \multicolumn{3}{|c||}{ Nivel de consistencia/Consistency level } \\
\cline { 2 - 4 } & Bueno/Good & Aceptable/Acceptable & Pobre/Poor \\
\hline $\begin{array}{c}\text { Umbral de consistencia } \\
\text { Consistency threshold }\end{array}$ & $\mathrm{C}>2(\mathrm{~m} / \mathrm{s})$ & $1<\mathrm{C} \leq 2(\mathrm{~m} / \mathrm{s})$ & $\mathrm{C} \leq 1(\mathrm{~m} / \mathrm{s})$ \\
\hline \hline
\end{tabular}

It can be observed that consistency level is determined by the $\sigma$ Ra value. In the best case, if such product is 0 , the consistency value will be 2,8, which corresponds to the best possible road, where operation speed is close to the average speed of the whole segment. If the value of such product is 32 , i.e. high speed variability, the $C$ value will be the lowest possible: 0 .

The average operation speed $\left(V_{\text {average }}\right)$ is estimated based on the weighted average for speed distances $\left(V_{i}\right)$ on each homogeneous segment $\left(L_{i}\right)$ of the road under study, as shown by Equation 2.

$$
V_{\text {media }}=\frac{\sum_{i=1}^{n} V_{i} L_{i}}{\sum_{i=1}^{n} L_{i}}
$$

The regularized area is described by $R a_{k}$ index in Equation 3. This index expresses the addition as absolute value of areas between average operation speed curves and speed profile regularized by the total distance. 
In this case, segment $k$ corresponds to the segment where there is a sign change as product of the intersection of two profiles. In most of the cases, segment $k$ length matches with segment $i$ length.

$$
R a_{k}=\frac{1}{\sum_{k=1}^{K} L_{k}} \sum_{k=1}^{K}\left\{\int_{l=0}^{L_{k}}|S(l)-\bar{S}| d l\right\}
$$

Figure 1 graphically depicts the elements of Equation 3 for 4 segments. In this way the Ra index is merely the regularized addition of $a_{k}$ areas expressed as absolute value. Figure 1 assumes that the average operation speed is constant alongside the road, which is not necessarily true in practice.

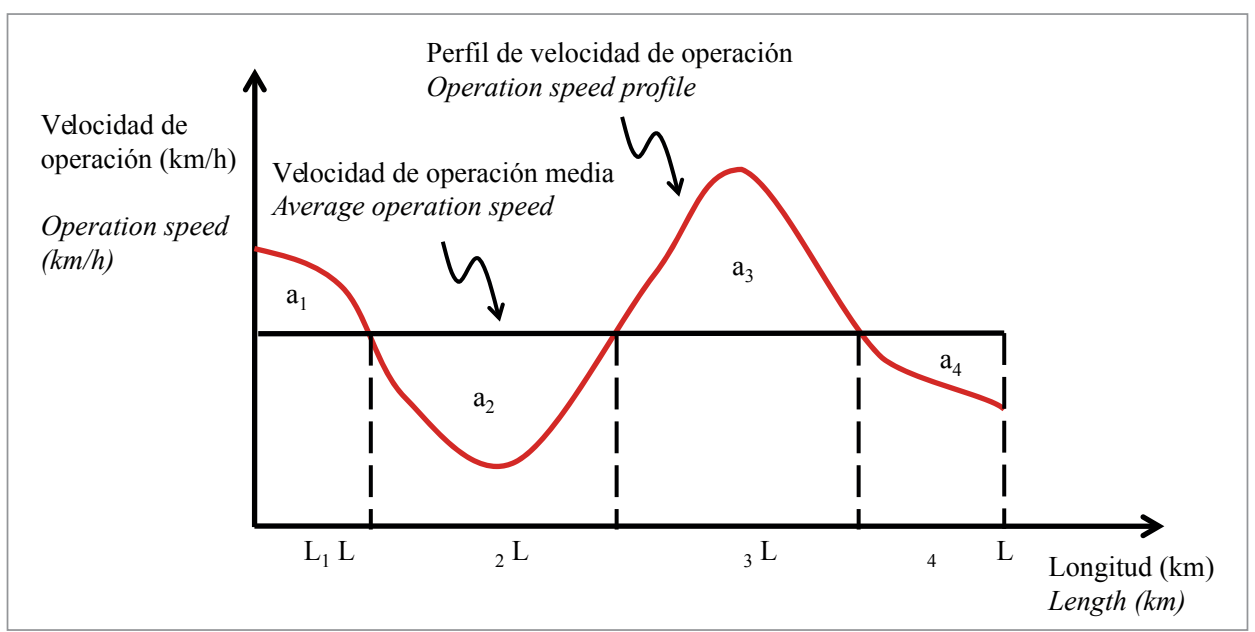

Figura 1. Parametros considerados para estimar el índice Ra (Adaptado de Polus et al., 2005)

Figure 1. Parameters considered for estimating Ra Index (Adaptation by Polus et al., 2005)

Contrarily to Lamm et al., (1988) method, Polus et al (2004) method requires an operation speed profile alongside $L$ length (see Figure 1). However, predictive models available on literature only solve this problem partially and, on the other hand; the only alternative for obtaining a continuous infield speed profile is by means of data collection using global positioning systems.

\section{Development of speed profiles using GPS}

\subsection{Measuring methods for speed operation}

There are few experiences developed for measuring continuous speed with GPS. Cafiso et al. (2005), Memon et al. (2008) and recently García and Camacho (2009) measured speed using GPS to develop speed profiles. However, such authors focused their studies on specific components of operation speed profile: acceleration and deceleration measurements, speed measurements on horizontal curves and their approaching tangents. The research done by Cafiso et al. (2005) is an exception, as long roads segments are also analyzed. 
All of them agree on the complexity to obtain an adequate sample size for estimating the 85 percentile of operation speed. If speed is measured by means of the car-following technique, it will be necessary to follow up at least 3 vehicles. At the same time it is necessary to estimate an error margin associated to the indirect estimation of the speed the leading vehicle is moving along. This error is essentially caused by gear changes and by spacing variability between leading vehicles and their followers, respectively. On the other hand, if speed is measured by using a drivers' sample, it will be necessary to obtain a stratified size sample to achieve a speed frequency distribution that includes fast, slow and regular drivers with homogeneous characteristics. Felipe and Navin (1998) proved that such consideration directly influences the elaboration of geometry-speed models.

Although Memon et al. (2008) demonstrated that there are no significant differences between speed profile values, it is necessary to verify this consideration case by case, since drivers behavior is conditioned by traffic regulations and local culture.

\subsection{Filtering speed records}

Speed record filtering is a tool that allows the identification and removal of anomalous data, which also connects positioning and speed data. There are several tools used for this purpose. However, Kalman filter is widely used (Kim y Langley, 2000). This filter is capable of solving at the same time detection of outliers, dropouts recovery due to satellite drops and connection of positioning, path and speed records obtained by GPS. Essentially the filter estimates the $x$ status of a signal, in discrete time, by means of a linear equation as Equation 4, from a raw data record as shown in Equation 5.

$$
\begin{aligned}
& \mathrm{x}_{\mathrm{k}}=\mathrm{Ax}_{\mathrm{k}-1}+\mathrm{Bu}_{\mathrm{k}-1}+\mathrm{w}_{\mathrm{k}-1} \\
& \mathrm{z}_{\mathrm{k}}=\mathrm{Hx}_{\mathrm{k}}+\mathrm{v}_{\mathrm{k}}
\end{aligned}
$$

Where $A, B$ and $H$ are regression parameters. $w$ and $v$ are random variables representing the noise and signal in the process, respectively. Therefore, $w$ and $v$ are independent mutants following a regular probability distribution which average is zero. Kalman filter predicts the status of $z$ and $x$ by minimizing the mean root square of the covariance process and eliminating $w$ and $v$ noise. In this case, speed data are represented by z signal and the resulting speed is obtained from $x$ value.

\subsection{Smoothening speed records}

After assembling and filtering data, a smoothening process is required in order to reduce the amount of instant speed records and to simplify the interpretation of speed profiles. 
Literature provides a wide variety of smoothening methods, such as crossed local regression, smoothening based on Kernels, double and single exponential smoothers, " $n$ " splines (TIBCO, 2008) and others quite sophisticated alternatives based on artificial intelligence and wavelets. Particularly, Rim et al. (2011) have employed the weighted local regression and exponential regression to deal with speed profiles. They concluded that independently of the method employed, the result is highly dependant on the smoothening parameters used. After revising these techniques, the Loess smoothening was selected. This smoothening method enables us to obtain, by means of a non-parametric regression around $x_{i}$ data point, an estimation of discrete data function $f\left(x_{i}\right)$ by assuming that noise $\varepsilon_{i}$ is normally distributed with average 0 and standard deviation $\sigma^{2}$ according to Equation 6.

$$
y i=f\left(x_{i}\right)+\varepsilon_{i}
$$

For smoothening purposes, this method applies least square regressions weighted on an $h$ data frame, which moves alongside the speed signal for each $x_{i}$ reference point. The weighted function is a three cubic function described in Equation 7, where $x_{0}$ is the datum used to define $h$ value.

$$
w_{i}=\left\{\begin{array}{cc}
\left(1-\left|\frac{x_{i}-x_{0}}{h}\right|^{3}\right)^{3} & ;\left|\frac{x_{i}-x_{0}}{h}\right|<1 \\
0 & ;\left|\frac{x_{i}-x_{0}}{h}\right| \geq 1
\end{array}\right.
$$

In this way, speed profile used to apply consistency assessment is free of outlier data, having speeding and positioning records together, without noise caused by small local accelerations.

\section{Speed profille models}

Predictive models of operation speed available on literature correspond to models applicable on specific elements of the road. Only the model by Fitzpatrick and Collins (2000) connects predictive equations of operation speed by using acceleration or deceleration rates to obtain a continuous speed profile. Applying such models requires a detailed knowledge of horizontal alignment, which is a datum not always available.

Calculation predictive model by Fitzpatrick and Collins (2000) is composed of 10 equations that enable the estimation of operation speed on horizontal curves which have diverse longitudinal slopes, including vertical curves and a combination of vertical and horizontal curves. 
In the same way the model proposes acceleration and deceleration values aimed to connect specific values for operation speed predicted by the models.

Table 2 summarizes the model by Fitzpatrick and Collins (2000), which is the only model that allows the estimation of a speed profile considering geometry in a full extent. The model is capable of estimating operation speeds on horizontal curves for different longitudinal slopes. In straight roads, it permits the consideration of the $K$ curve parameter effect on the speed for the case of concave and convex curves considering the visibility limitation effect. In this way, the model by Fitzpatrick and Collins (2000) delivers several calculation choices, which consider geometric design.

However, the model has several limitations. Among them, it does not allow the consideration of the intersection tangent effect between curves and counter curves, which lead to a potential speed overestimation on the counter curve. Similarly, on straight roads the model requires expected speed data, which is not always available. Therefore speed is usually associated with the legal speed limit, which is mistaken taking into account that speed should be the 99 percentile of operation speed.

On the other hand, for the model application a detailed knowledge of highway geometrical design is required, which are not always available. It leads to a necessary inference of geometry in a direct way by means of a topographic uplifting or, in an indirect way by means of GPS measurements, as conducted in this research job.

Tabla 2. Modelos predictivos de velocidad de operación de Fitzpatrick y Collins (2000)

Table 2. Predictive models of operation speed by Fitzpatrick and Collins (2000)

\begin{tabular}{|c|c|c|c|c|}
\hline $\begin{array}{l}\text { Geometría Horizontal } \\
\text { Horizontal Geometry }\end{array}$ & $\begin{array}{c}\text { Geometría } \\
\text { Vertical } \\
\text { Vertical Geometry }\end{array}$ & $\begin{array}{l}\text { Velocidad de operación } \\
\qquad(\mathrm{km} / \mathrm{h}) \\
\text { Operation speed }(\mathrm{km} / \mathrm{h})\end{array}$ & $\begin{array}{l}\text { Deceleración }\left(\mathrm{m} / \mathrm{s}^{2}\right) \\
\text { Deceleration }\left(\mathrm{m} / \mathrm{s}^{2}\right)\end{array}$ & $\begin{array}{l}\text { Aceleración }\left(\mathrm{m} / \mathrm{s}^{2}\right) \\
\text { Acceleration }\left(\mathrm{m} / \mathrm{s}^{2}\right)\end{array}$ \\
\hline Curva/ Curve & $-9 \%<\mathrm{i}<-4 \%$ & $V_{85}=102,1-\frac{3077,13}{R}$ & \multirow{4}{*}{$\begin{array}{ccc}1,00 & ; & \mathrm{R} \leq 175 \mathrm{~m} \\
0,6794-\frac{295,14}{R} & ; & 175<\mathrm{R} \leq 436 \mathrm{~m} \\
0,00 \quad & ; & \mathrm{R}>436 \mathrm{~m}\end{array}$} & \multirow{4}{*}{$\begin{array}{ll}0,54 ; & 175<\mathrm{R} \leq 250 \mathrm{~m} \\
0,43 ; & 250<\mathrm{R} \leq 436 \mathrm{~m} \\
0,21 ; & 436<\mathrm{R} \leq 875 \mathrm{~m} \\
0,00 ; & \mathrm{R}>875 \mathrm{~m}\end{array}$} \\
\hline Curva/ Curve & $-4 \%<\mathrm{i}<0 \%$ & $V_{85}=105,98-\frac{3709,90}{R}$ & & \\
\hline Curva/ Curve & $0 \%<\mathrm{i}<4 \%$ & $V_{85}=104,82-\frac{3574,51}{R}$ & & \\
\hline Curva/ Curve & $4 \%<\mathrm{i}<9 \%$ & $V_{85}=96,61-\frac{2752,19}{R}$ & & \\
\hline Curva/ Curve & $\begin{array}{l}\text { Curva Cóncava } \\
\text { Concave curve }\end{array}$ & $V_{85}=103,24-\frac{3576,51}{R}$ & 1,00 & 0,54 \\
\hline Curva/ Curve & $\begin{array}{l}\text { Curva Convexa } \\
\text { Convex curve }\end{array}$ & (1) & (2) & (2) \\
\hline Recta/Straight & $\begin{array}{l}\text { Curva Cóncava } \\
\text { Concave curve }\end{array}$ & $\begin{array}{c}\mathrm{V}_{85}=\text { velocidad deseada } \\
\text { expected speed }\end{array}$ & $\begin{array}{l}\text { No aplicable } \\
\text { Not applicable }\end{array}$ & $\begin{array}{l}\text { No aplicable } \\
\text { Not applicable }\end{array}$ \\
\hline Recta/Straight & $\begin{array}{l}\text { Curva Convexa } \\
\text { Convex curve }\end{array}$ & $\begin{array}{c}\mathrm{V}_{85}=\text { velocidad deseada (3 } \\
\text { expected speed) }\end{array}$ & $\begin{array}{l}\text { No aplicable } \\
\text { Not applicable }\end{array}$ & $\begin{array}{l}\text { No aplicable } \\
\text { Not applicable }\end{array}$ \\
\hline Recta/ Straight & $\begin{array}{l}\text { Curva Convexa } \\
\text { Convex curve }\end{array}$ & $V_{85}=105,08-\frac{149,69}{K}(3)$ & 1,00 & 0,54 \\
\hline
\end{tabular}

Notas: (1) usar ecuaciones para curvas en pendientes; (2) usar aceleraciones y deceleraciones para curvas en pendiente (3): considerar visibilidad restringida

Notes: (1) using equations for curves on slopes; (2) using accelerations and decelerations for curves on slopes; (3) considering restricted visibility 


\section{Study case}

The objective of this case of study was to compare consistency analysis results obtained by means of continuous measurements and using the model by Fitzpatrick and Collins (2000). This model was selected as there are no predictive models of calibrated speed profiles available in Chile. The comparison intends to dimension the error extent, which is likely to be made when analyzing consistency with calibrated models in regards to the use of in-field measurements.

In the first place measurement segments were selected on diverse roads of Chile, where GPS speed measurements were conducted. In an approximated way geometrical parameters were estimated on such roads, in order to apply the model by Fitzpatrick and Collins (2000). Then speed data were processed so as to obtain measured speed profiles and the speed profile was developed based on the selected predictive model. Both profiles were later used for the consistency analysis by using Polus method.

\subsection{Selection of sections measurements}

In order to conduct the consistency analysis Chilean roads were selected, which have diverse geometrical conditions, such as curvature and longitudinal slope, located on different topographic environments as plain, undulated and mountainous areas. All sections are two-lane roads each runway running in opposite direction, each lane of 3,5 $\mathrm{m}$ constant width and berm of 0,5m constant width. For all studied sections, traffic level was lower than 10.000 vehicles/day-year. At the moment measurements were conducted, the traffic level happened to be quite slow; therefore there were no interferences at all. Table 3 summarizes the characteristics of sections used for consistency analysis on site. Road 4 was segmented into 2 sections due to its diverse topographic conditions as it was assumed that these could affect consistency index calculation.

Tabla 3. Características generales de los tramos analizados

Table 3. General characteristics of analyzed sections

\begin{tabular}{||c|c|c|c|c|c||}
\hline $\begin{array}{c}\text { \# Ruta/ } \\
\text { \#Road }\end{array}$ & $\begin{array}{c}\text { Longitud }(\mathbf{k m}) \\
\text { Length }(\mathbf{k m})\end{array}$ & $\begin{array}{c}\text { Topografía } \\
\text { Topography }\end{array}$ & $\begin{array}{c}\text { Pendiente (\%) } \\
\text { Slope (\%) }\end{array}$ & $\begin{array}{c}\text { \# Curvas horizontales } \\
\text { \# Horizontal curves }\end{array}$ & $\begin{array}{c}\text { \# Registros de velocidad/ } \\
\text { \# Speed records }\end{array}$ \\
\hline 1 & 3 & Ondulado/Undulated & 4,2 & 10 & 3.000 \\
\hline 2 & 13 & Ondulado/Undulated & 3,5 & 18 & 13.000 \\
\hline 3 & 13 & Ondulado/Undulated & 3,9 & 35 & 13.000 \\
\hline $4-1$ & 2 & Plano/ Plain & 3,0 & 44 & 2.000 \\
\hline $4-2$ & 4 & Montañoso/ Mountainous & 8,0 & & 4.000 \\
\hline
\end{tabular}

\subsection{Collection of operation speed data}

Speed data were collected from roads in Table 3 by means of a GPS of $10 \mathrm{~Hz}$ installed on a lightweight vehicle. The device was installed on the vehicle windshield and its antenna on the roof, just on the central longitudinal axle. GPS device collects speed data every 0,1 sec. 
with an accuracy of $0,1 \mathrm{~km} / \mathrm{h}$ for speed, $3 \mathrm{~cm}$ for horizontal position and $0,1^{\circ}$ for the azimuth. The device is also capable of triangulating up to 8 satellites in motion, which allows obtaining a stable signal during data collection (Racelogic, 2008).

During data collection process conducted in site, a lightweight vehicle moved along 5 times, so as to obtain a set of speed profiles for accuracy control and to develop a unique speed profile. In all cases the vehicle ran in absence of traffic in order to avoid interferences with other vehicles. In site measuring and quality control process was developed by following recommendations described by Echaveguren et al. (2011). Such recommendations suggest marking the beginning and ending to connect repeated measurements and evaluating repeatability and reproducibility. Thus detecting wrong signals or outliers and checking whether a measurement needs to be repeated or it will be only necessary to filter such outliers later.

Consequently it was possible to repeat the measuring experience with a small size sample on site, which is quite representative of operation speed.

\subsection{Data Processing for operation speed}

Each speed profile measured with the GPS device was filtered by using Kalman filter and it was smoothed by employing Loess method of order 2, with a smoothening frame between 0,03 and 0,05. These smoothening parameters were obtained by minimizing root mean square (RMS). Figure 2 shows an example of a measured and filtered speed profile and a smoothened speed profile for road 2.

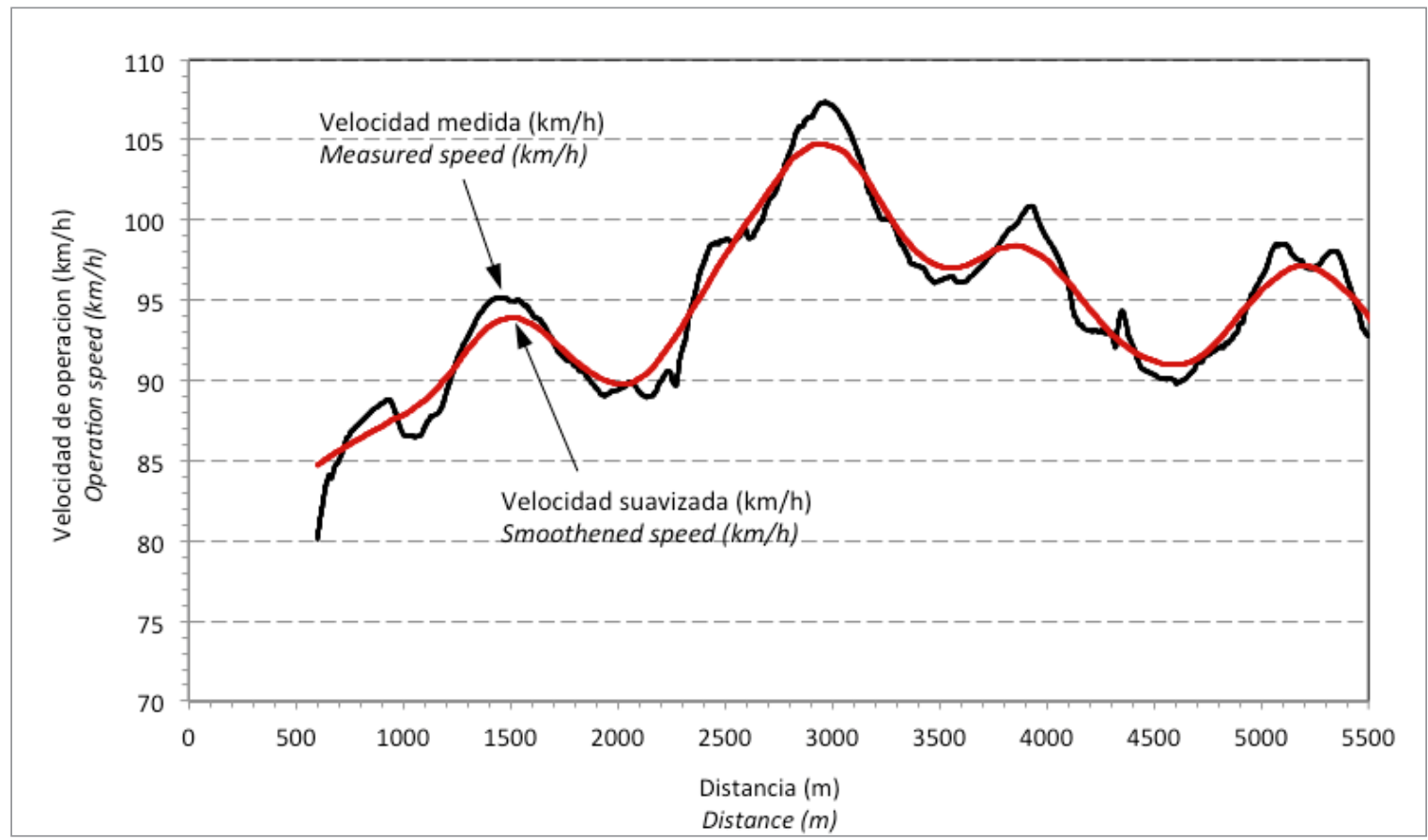

Figura 2. Ejemplo de perfil de velocidad suavizado en ruta $2(\mathrm{~km} 0+600 \mathrm{al} \mathrm{km} \mathrm{5+500)}$

Figure 2. Example of smoothed speed profile on route 2 ( $\mathrm{km} 0+600$ up to $\mathrm{km} \mathrm{5+500)}$ 
Table 4 summarizes the results obtained after smoothening process, which are then used as inputs to apply the consistency assessment by means of Polus method. Differences of average speed can be observed on each segment.

Tabla 4. Resumen de datos de perfil de velocidad de operación procesado

Table 4. Summary of processed operation speed profile

\begin{tabular}{|c|c|c|c|c|c||}
\hline $\begin{array}{c}\text { Ruta } \\
\text { Road }\end{array}$ & $\begin{array}{c}\text { \# Datos de velocidad } \\
\text { \#Speed inputs }\end{array}$ & $\begin{array}{c}\text { Parámetro de suavización } \\
\text { Smoothening parameter }\end{array}$ & RMS (km/h) & $\begin{array}{c}\text { Velocidad media } \\
\mathbf{( k m} / \mathbf{h})\end{array}$ & $\begin{array}{c}\text { Desviación } \\
\text { estándar (km/h) } \\
\text { Standard } \\
\text { Average Speed (km/h) }\end{array}$ \\
\hline 1 & 2.700 & 0,05 & 7,8 & 60,5 & 11,1 \\
\hline 2 & 12.200 & 0,05 & 1,2 & 92,2 & 6,4 \\
\hline 3 & 13.580 & 0,03 & 8,6 & 74,3 & 9,5 \\
\hline $4-1$ & 1.900 & 0,05 & 8,4 & 70,4 & 7,3 \\
\hline $4-2$ & 4.000 & 0,03 & 6,4 & 38,9 & 7,7 \\
\hline
\end{tabular}

RMS: Root mean square error (Error cuadrático medio)/ RMS: Root mean square

From Table 4 it can be concluded that:

- Route 1 concentrates variability on a specific road segment;

- $\quad$ Route 2 has the lowest operation speed variability;

- $\quad$ Route 3 has a high variability alongside the whole measured segment;

- On segments 4-1 and 4-2 there is a difference between average speeds of almost $30 \mathrm{~km} / \mathrm{h}$, which evidences significant road differences. This result confirmed the need of segmenting the road before applying Polus method. In this way it is possible to avoid hiding poor/regular consistency segments at the immediate previous consistency level.

\subsection{Operation speed profiles from Fitzpatrick and Collins model}

This speed profile corresponds to a theoretical profile, which requires a previous and detailed knowledge of the road geometry to be assessed. In this case construction drawings were not available; therefore geometry was reached by means of heading, radius, relative height and operation speed records obtained by the GPS device. From these data $(R)$ radius, (i) longitudinal slope, $(w)$ deflexion angle, curves beginnings and endings were obtained. From these data operation speeds, accelerations and decelerations were calculated using Table 2. Then operation speed values were assigned to geometry and a theoretical operation speed profile was built up. It is important to highlight that the model employed was not calibrated in Chile, therefore it was used as a reference to determine the variation of consistency regarding direct measurement.

\subsection{Comparing measured and modeled speed profiles}

A comparison was carried out between measured and modeled speed profiles, in order to visualize potential differences on consistency assessment results. 
Studied segments are graphically depicted in Figure 3. An analysis of variance (ANOVA) - with a variable for repeated measurements - and a cross-correlation analysis were applied on both profiles in order to obtain measurement differences. Analysis showed that measured and modeled profiles are statistically different for all roads, because:

- Modeled profiles averages are higher than the ones measured in a range varying from 5 to $40 \mathrm{~km} / \mathrm{h}$

- ANOVA showed that average differences are statistically significant as all comparisons delivered a value $p=0,000$ for a $95 \%$ significance level

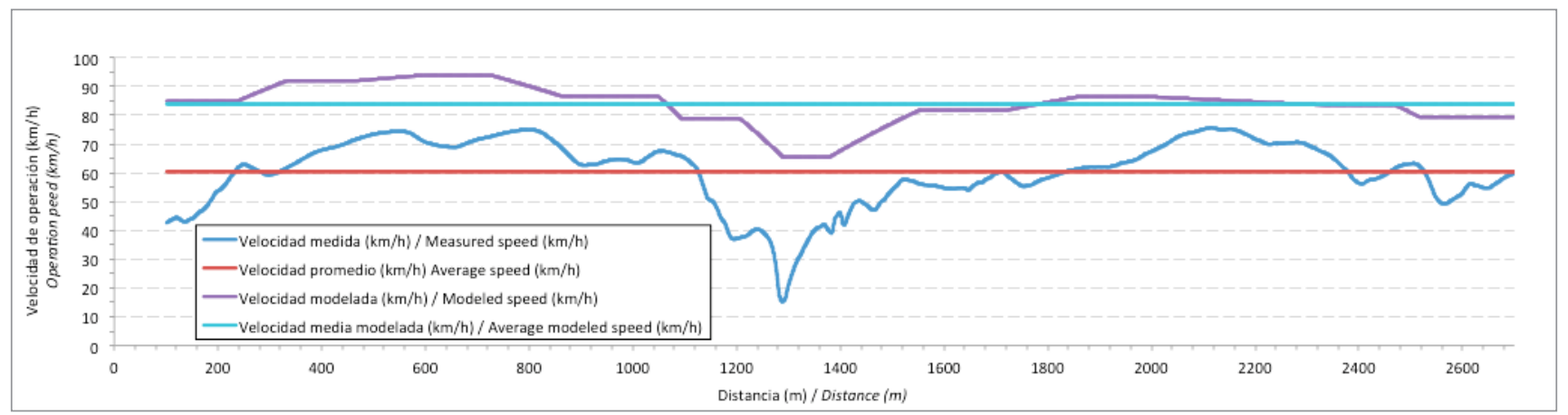

Figura 3a. Ejemplos de gráficas de perfiles de velocidad medidos y modelados para ruta 1

Figure 3a. Depicted examples of speed profiles measured and modeled for road 1

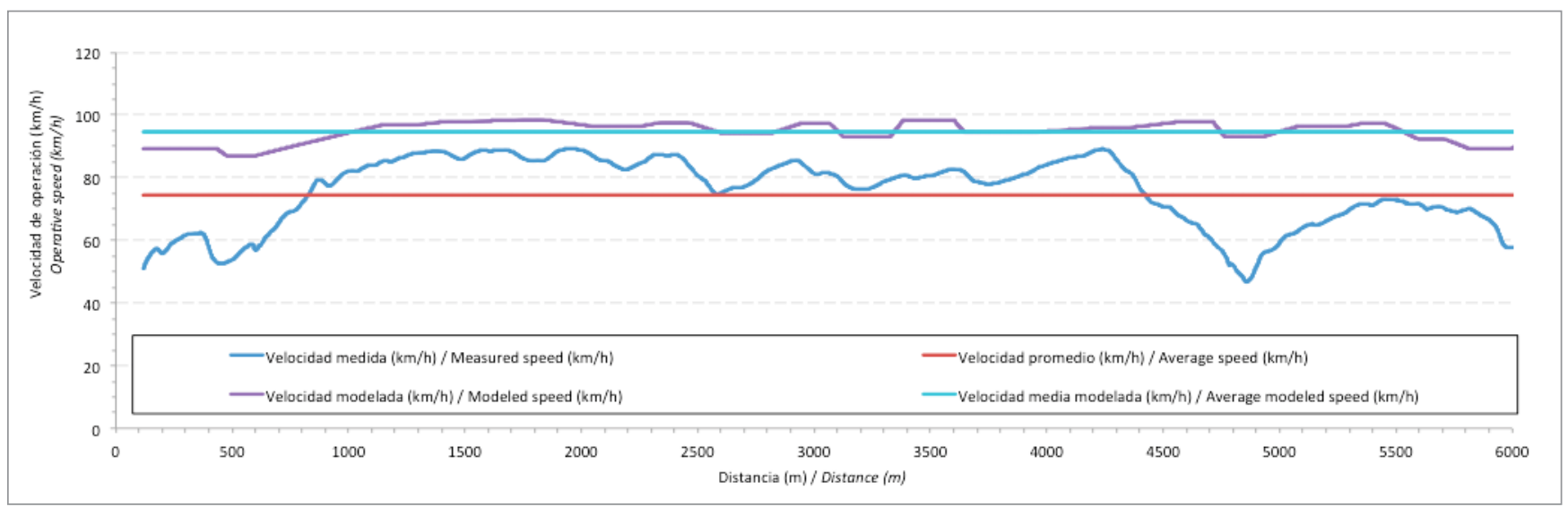

Figura 3b. Ejemplos de gráficas de perfiles de velocidad medidos y modelados para ruta 3

Figure $3 \boldsymbol{b}$. Depicted examples of speed profiles measured and modeled for road 3

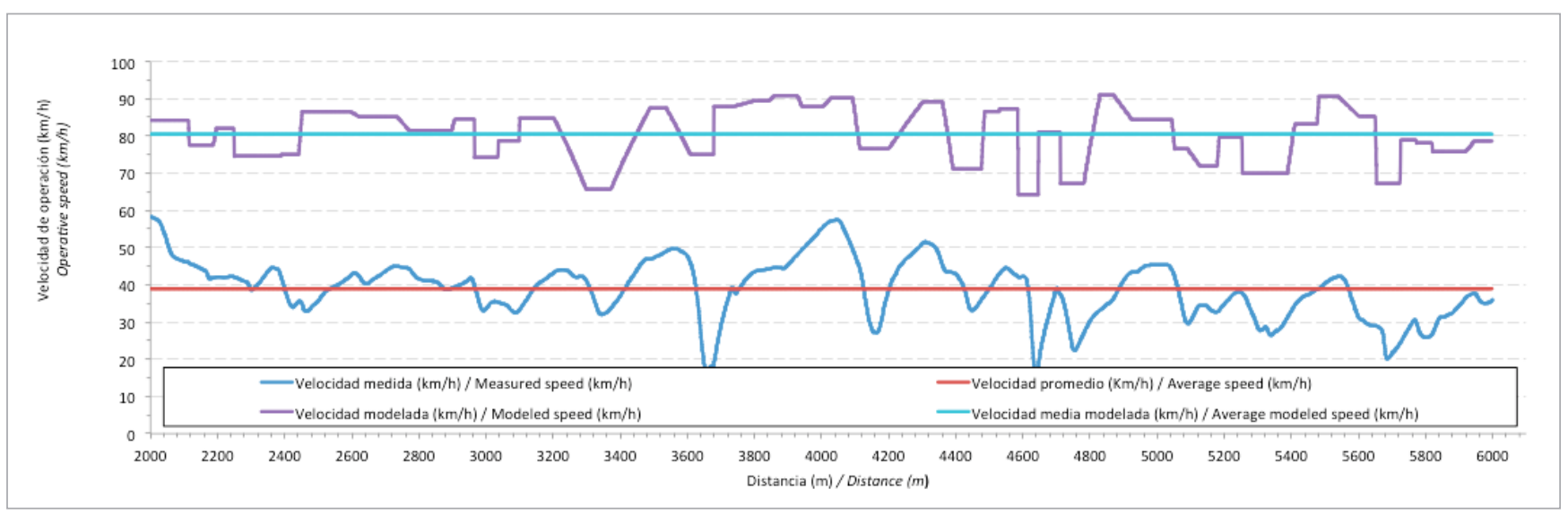

Figura 3c. Ejemplos de gráficas de perfiles de velocidad medidos y modelados para ruta 5

Figure 3c. Depicted examples of speed profiles measured and modeled for road 5 


\subsection{Consistency assessment}

Consistency assessment was carried out by employing Equations 1, 2 and 3 for speed records obtained with a GPS and, also the equations in Table 2 for the modeled speed profile.

Table 5 summarizes the consistency analysis results by using speed profile measurements. Table 6 shows the results of consistency analysis using predictive models. Results in Table 5 show that road 2 is at an "acceptable" consistency level while the other roads are at a "poor" consistency level (roads 1 and 3). Roads 4-1 and 4-2 are quite closer to "poor" - "acceptable" consistency threshold. This is mainly because of the high standard deviation of operation speed in regards to the segment average speed.

Tabla 5. Parámetros de consistencia obtenidos para cada segmento de ruta analizado usando perfiles de velocidad medidos

Table 5. Consistency parameters obtained for each road segment using measured speed profiles

\begin{tabular}{|c|c|c|c|c|c|c|}
\hline \multirow[t]{2}{*}{ Ruta/ Road } & \multirow{2}{*}{$\begin{array}{c}\text { Velocidad media } \\
\qquad(\mathrm{km} / \mathrm{h}) \\
\text { Average speed }(\mathrm{km} / \mathrm{h})\end{array}$} & \multicolumn{2}{|c|}{$\begin{array}{c}\text { Desviación estándar } \\
\text { Standard deviation }\end{array}$} & \multirow[t]{2}{*}{$\operatorname{Ra}\left(\mathrm{m}^{2} / \mathrm{s}\right)$} & \multirow[t]{2}{*}{$C(\mathrm{~m} / \mathrm{s})$} & \multirow{2}{*}{$\begin{array}{l}\text { Nivel de consistencia } \\
\text { Consistency level }\end{array}$} \\
\hline & & $(\mathrm{km} / \mathrm{h})$ & $(\mathrm{m} / \mathrm{s})$ & & & \\
\hline 1 & 60,5 & 11,1 & 3,1 & 2,3 & 0,4 & Pobre/ Poor \\
\hline 2 & 92,2 & 6,4 & 1,8 & 1,4 & 1,4 & Aceptable/ Acceptable \\
\hline 3 & 74,3 & 9,5 & 2,6 & 2,2 & 0,6 & Pobre/ Poor \\
\hline $4-1$ & 70,4 & 7,0 & 2,0 & 1,6 & 1,1 & Aceptable/ Acceptable \\
\hline $4-2$ & 38,9 & 7,7 & 2,1 & 1,7 & 1,0 & Aceptable/ Acceptable \\
\hline
\end{tabular}

Contrarily, Table 6 shows that when using the speed profile model, all consistency levels improve systematically. This is due to the smoothening effect on the average speed induced by models using independent equations for each geometry entity, which is employed to estimate operation speed.

Tabla 6. Parámetros de consistencia obtenidos para cada segmento de ruta analizado usando modelos de perfiles de velocidad

Table 6. Consistency parameters obtained for each analyzed road segment by using speed profile models

\begin{tabular}{|c|c|c|c|c|c|c|}
\hline \multirow{2}{*}{ Ruta/ Road } & \multirow{2}{*}{$\begin{array}{c}\text { Velocidad media } \\
(\mathrm{km} / \mathrm{h}) \\
\text { Average speed }(\mathrm{km} / \mathrm{h})\end{array}$} & \multicolumn{2}{|c|}{$\begin{array}{l}\text { Desviación estándar } \\
\text { Estándar deviation }\end{array}$} & \multirow{2}{*}{$\operatorname{Ra}\left(\mathbf{m}^{2} / \mathrm{s}\right)$} & \multirow{2}{*}{$C(\mathrm{~m} / \mathrm{s})$} & \multirow{2}{*}{$\begin{array}{l}\text { Nivel de consistencia } \\
\text { Consistency level }\end{array}$} \\
\hline & & $(\mathrm{km} / \mathrm{h})$ & $(\mathrm{m} / \mathrm{s})$ & & & \\
\hline 1 & 83,7 & 6,6 & 1,8 & 1,4 & 1,4 & Aceptable/Acceptable \\
\hline 2 & 97,4 & 0,9 & 0,3 & 0,1 & 2,8 & Bueno/Good \\
\hline 3 & 94,7 & 2,7 & 0,8 & 0,6 & 2,5 & Bueno/ Good \\
\hline $4-1$ & 93,7 & 4,0 & 1,1 & 1,0 & 2,1 & Bueno/ Good \\
\hline $4-2$ & 80,4 & 7,0 & 2,0 & 1,7 & 1,1 & Aceptable/Acceptable \\
\hline
\end{tabular}

A relevant aspect is that the method assesses consistency based on the own operation condition of each segment. Therefore, it doesn't necessarily means that the presence of speed differences on long segments will lead to inconsistency in the inside section of the segment. This was visualized on roads 4-1 and 4-2, that in spite of showing different average speeds, consistency happened to be approximately the same in the inside segment. 
At the same time, the method proposed by Polus, which is employed in this study, does not solve by itself the inconsistencies of gear changes. Once again segments 4-1 and 4-2 confirm this situation, since Polus model is not capable of analyzing a gear change from an average speed of $70,4 \mathrm{~km} / \mathrm{h}$ down to $39,8 \mathrm{~km} / \mathrm{h}$. However, this is likely to be solved in an iterative way: identifying structural changes of average speed on site by calculating real time average travelling speed, as well as applying a dynamic segmentation process previously to consistency analysis. In such a case, segmentation should only be considered in function of average speed, because if standard deviation is included, it will be possible to obtain short segments with high consistency, which is not true in practice.

By employing the modeled speed profile, standard deviations decrease due to the models' inability to properly predict expected speed and the minimum speed in curves of different directions, which reduces speed variations between horizontal curves. At lower speed standard deviation, the Ra value necessarily tends to drop and, therefore, $C$ value of consistency tends to be higher. This is an independent situation from modeled speed value, which also tends to overestimate operation speed. Above provides an explanation for the significant consistency variations on road 3 for instance, passing from "poor" to "good" level when using a theoretical model of speed profile.

\section{Conclusions}

This study debated the consistency analysis by means of Polus method, which is an aggregated method of consistency. Special attention was focused on the continuous speed profile procurement and processing, provided their relevance when employing this method. The results from consistency assessment, obtained by using a theoretical model of speed profile, were also compared. The following conclusions were achieved from this study:

The Polus method for consistency analysis enables analyzing long roads segments, which provides it with advantages over other consistency analysis methods. However, the main limitations observed during its application were the following.

- The method requires continuous operation speed profiles, either measured or modeled. On one hand, continuous operation profiles can only be measured by means of global positioning technology. On the other hand, there are few continuous operation speed models available on literature and they are mainly focused on road components. These models tend to smooth speed standard deviation and, therefore, they overestimate the consistency level. Modeling task must be focused on incorporating three-dimensional characteristics of the road segment geometry and, it must also be focused on the effects on the operational speed. 
- In cases where there are significant changes of average speed, and consequently changes of geometrical design, the method is not able to determine the effect of such changes on the consistency value. This is a relevant aspect for the design of transition speed zones. Results obtained for 4-1 and 4-2 roads depict such limitation. In order to overcome this situation, it is necessary to employ an iterative process by applying dynamic segmentation principles or by applying the theory of sudden changes in data series.

- $\quad$ Since consistency is determined in function of the segment average speed, it is necessary to assume that it is a good representation of speed design (or project design) of a road. This assumption is not necessarily true when segments are highly inconsistent. This may lead to underrate the inconsistency of a road.

- Consistency thresholds proposed by Polus model are similar to those thresholds proposed by Lamm, which are in turn only valid for horizontal curves with low longitudinal slopes. Nevertheless, these thresholds are considered as adequate for analyzing a profile level as long as empirically-validated values are not included.

The use of continuous operation speed techniques (or discrete signals with high data density) imposes the need to conduct a detailed data post-process in order to eliminate background noise, to assembly speed and position signals, to eliminate local speed variations and to condense data by means of a smoothening process. Tools employed in this research job, mainly Kalman filter and Loess smoothening method, facilitate an adequate post-processing task and they are easily programmed.

Speed profile models are useful when new road segments are evaluated, because direct measurements of operation speed are not available. Due to theoretical speed profiles limitations, it is always recommended to evaluate consistency using direct measurements of operation speeds from existing roads.

In practical terms, special attention should be given to the treatment of opposite speed signals; so as to avoid scoring the acceleration needed to start the trial vehicle and its deceleration when stopping the same vehicle. In such cases, it is suggested to start and end measurements on long tangents, so as to avoid missing data for the analysis.

Polus method explains consistency mainly by means of speed standard deviation and Ra value. The model preliminary analyses as well as the application results show that inverse proportionality is coherent between the operation speed variability and consistency: the higher variability, the lower consistency, independently from the segment average speed value. 


\section{Acknowledgemnts}

The author wishes to thank to the National Scientific and Technological Development Fund (FONDECYT) of Education Ministry of Chile, for financing the project FONDECYT 11090029, which supports this research job.

\section{Referencias/ References}

Cafiso S., Digrazziano A. y La Cava G. (2005), Actual driving data analysis for design consistency evaluation. Transportation Research Record, 1912, 19-30.

Cox R. y Arndt O. (2010), Australian experience with using speed predictions models to determinate accurate design speeds. Paper 70. 4th International Symposium on Highway Geometric Design. España.

Echaveguren T., Altamira A., Vargas-Tejeda S., y Riveros M.D. (2009), Criterios para el análisis de consistencia del diseño geométrico: velocidad, fricción, visibilidad y criterios agregados. Artículo A-59. XV Congreso Argentino de Vialidad y Tránsito. Argentina.

Echaveguren T. (2010) Modelos de velocidad de operación. Estado del arte. Documento de Investigación DT - 01/10, FONDECYT 11090029. Universidad de Concepción. Chile.

Echaveguren T., Sepúlveda P. y Vargas-Tejeda S. (2011), Evaluación de precisión de mediciones de velocidad de operación en carreteras obtenidas con GPS. Articulo 91. XV Congreso Chileno de Ingeniería de Transporte. Chile.

Felipe E. y Navin, F. (1998), Automobiles on horizontal curves. Experiment and observations. Transportation Research Record, 1628, $50-56$.

Fitzpatrick K. y Collins J. (2000), Speed profile model for two-lane rural highways. Transportation Research Record, $1737,42-49$.

García A. y Camacho A. (2009), Evaluación de la seguridad vial de carreteras convencionales mediante la determinación de la consistencia global de su diseño geométrico. Carreteras, 163, 21 - 32.

Kim D. y Langley R. (2000), Kalman-filter-based GPS ambiguity resolution for real-time long-baseline kinematic applications. Workshop of the Central European Initiative (CEI) WG: Satellite Navigation Systems, Polonia.

Lamm R., Chueiri E., Hayward J. y Paluri A. (1988), Possible design procedure to promote design consistency in highway geometric designo n two-lane rural roads. Transportation Research Record, 1195, 111 - 122.

Memon A., Khaskheli G. y Qureshi A. (2008), Operating speed models for two-lane rural roads in Pakistan. Canadian Journal of Civil Engineering, 35(5), $443-453$.

Pérez A., García A., Camacho F. y D'Attoma P. (2010), Modeling operating speed and deceleration on two-lane rural roads with global positioning system data. Transportation Research Record, 2171, $11-20$.

Polus A., Pollatscheck M. y Mattar-Habibb C. (2004), New consistency model for rural highways and its relationship to safety. Journal of Transportation Engineering, 130(3), 286 - 293.

Polus A., Pollatscheck M., Mattar-Habibb C. y Jarroush J. (2005), An enhanced, integrated design-consistency model for both level and mountainous highways and its relationships to safety. Road \& Transport Research, 14(4), $13-26$.

Racelogic (2008), VBox mini User Guide. Racelogic Inc. Reino Unido.

Rim H., Oh Ch., Park J. y Lee G. (2011), Correction of erroneous vehicle speed data with locally weighed regression for GPS - based probe vehicle monitoring. 90th TRB Annual Meeting. Estados Unidos.

TIBCO (2008) TIBCO Spotfire S+(R) 8.1. Guide to statistics. TIBCO Sofware Inc. Estados Unidos.

Zhao W., Goodchild A. y McCormack E. (2011), Evaluating the accuracy of spot speed data from global positioning systems for estimating truck travel speed. Transportation Research Record, 2246, $101-110$. 